DOI: 10.20472/IAC.2018.038.036

MEHLIKA SARAÇ

Uludağ University, Turkey

REETA RAINA

FORE School of Management, India

\title{
ORGANIZATIONAL COMMITMENT AND INTENTION TO LEAVE : THE MODERATING ROLE OF UNCERTAINTY AVOIDANCE
}

\begin{abstract}
:
Research related to Industrial and Organizational Psychology has long been criticized for limiting its scope within single cultural context and not considering culture as a critical contingency variable to explain organizational behavior and human resources management (HRM) practices. This puts constrains upon both theories and practical solutions to the organizational problems (Barrett and Bass, 1976). The values-as-moderators framework has provided interesting information leading to a better understanding of the antecedents (Farh et al., 2007; Gelade et al., 2008) and consequences (Cohen, 2006; Johnson and Chang, 2006; Wasti and Can, 2008; Yao and Wang, 2006, García-Cabrera and García-Soto, 2011) of some work related attitudes.

Tendency to avoid uncertainty in organizations varies along with the tendency to avoid ambiguities in society at large, which is a major component of national culture. Hofstede conceptualize uncertainty avoidance with three components: rule orientation, employment stability and stress and defined as "the extend to which a society feels threatened by uncertain and ambiguous situations by establishing more formal rules, by not tolerating deviant ideas and behaviors, and believing in absolute truths and attainments of expertise" (Hofstede, 1980: 46).

This study assumes that since employees high in uncertainty avoidance have greater tendency to rules, loyalty and emotional attachment to work and organization, they have strong desire to stay with the organization based on a sense of duty/ obligation or emotional attachment and they have fewer intentions to leave the organization than employees low in uncertainty avoidance. Therefore, the study attempts to investigate the moderating effect of one of the components of national culture, "value-uncertainty avoidance" by focusing the differences between Turkey and India. Using data collected simultaneously from India and Turkey, authors conducted multi group structural equation modeling (SEM) approach to compare the relationship between organizational commitment and intention to leave across samples from two nations.
\end{abstract}

\section{Keywords:}

uncertainty avoidance, structural equation modeling, intention to quit, affective commitment, normative commitment, cross-cultural differences 